\title{
The best treatment for adolescent idiopathic scoliosis: what do current systematic reviews tell us? Lori Dolan* and Stuart Weinstein
}

\author{
Address: University of Iowa Healthcare, Iowa, USA
}

* Corresponding author

from $5^{\text {th }}$ International Conference on Conservative Management of Spinal Deformities

Athens, Greece. 3-5 April 2008

Published: 15 January 2009

Scoliosis 2009, 4(Suppl I):O67 doi:I0.II86/I748-7|6|-4-SI-O67

This abstract is available from: http://www.scoliosisjournal.com/content/4/SI/O67

(c) 2009 Dolan and Weinstein; licensee BioMed Central Ltd.

\section{Introduction}

Systematic reviews, the explicit combination of findings from multiple studies, can provide reliable and accurate conclusions about the effectiveness of interventions. This presentation summarizes six existing systematic reviews of non-operative treatments for AIS and discusses the practical implications of the findings.

\section{Materials and methods}

The Cochrane, Medline, DARE (Database of Abstracts of Reviews of Effects), and ACP Journal Club databases were searched for meta-analyses and systematic reviews of AIS treatment. The reviews were scored using the Oxman and Guyatt Overview Quality Assessment Questionnaire (OQAQ) to assess the scientific quality of the materials and methods leading to the conclusions.

\section{Results}

The search yielded six studies [1-7]. The major objectives included effectiveness of mass screening, exercises, bracing, observation and electrical stimulation. Based on the OQAQ scores, the Rowe review is extensively flawed, and its recommendations should be questioned. The Focarile and the Lenssinck reviews were the highest quality in this series, and as such, their recommendations should be considered the most valid and informative concerning treatment decisions.

\section{Conclusion}

Systematic reviews differ in quality, and all are limited by the availability and quality of published clinical evidence. Where level III and IV studies predominate, as in the case of AIS, systematic reviews may produce contradictory or inconclusive results. Such is the state of knowledge regarding bracing - the balance of published evidence neither supports nor prohibits using a brace to treat scoliosis in the growing child.

\section{References}

I. Focarile FA, Bonaldi A, Giarolo MA, et al.: Effectiveness of nonsurgical treatment for idiopathic scoliosis. Overview of available evidence. Spine 1991, 16:395-401.

2. U.S. Preventive Services Task Force: Screening for Idiopathic Scoliosis in Adolescents: Recommendation Statement [Agency for Healthcare Research and Quality]. 2004 [http:// www.ahrq.gov/clinic/3rduspstf/scoliosis/scoliors.htm].

3. United States Preventive Services Task Force: Screening for adolescent idiopathic scoliosis. Review article. Center for Evidence Based Medicine. Oxford Centre for Evidence-based Medicine Levels of Evidence. JAMA 1993, 269:2667-72 [http:// www.cebm.net/levels of evidence.asp\#levels].

4. Rowe DE, Bernstein SM, Riddick MF, et al.: A meta-analysis of the efficacy of non-operative treatments for idiopathic scoliosis. J Bone Joint Surg (Am) 1997, 79:664-74.

5. Negrini S, Antonini G, Carabalona R, et al.: Physical exercises as a treatment for adolescent idiopathic scoliosis. A systematic review. Pediatr Rehabil 2003, 6:227-35.

6. Lenssinck ML, Frijlink AC, Berger MY, et al.: Effect of bracing and other conservative interventions in the treatment of idiopathic scoliosis in adolescents: a systematic review of clinical trials. Phys Ther 2005, 85: 1329-39.

7. Dolan LA, Weinstein SL: Surgical rates after observation and bracing for adolescent idiopathic scoliosis: an evidencebased review. Spine 2007, 32:S9I-SI00. 